\title{
Synthesis, High-resolution Crystal Structure Refinement and Magnetic Properties of the Manganese-rich Cementite-type $\mathrm{Mn}_{1.8} \mathrm{Fe}_{1.2} \mathrm{C}$
}

\author{
Ludwig Stork, Paul Müller, Manfred Speldrich, Paul Kögerler, Jörg von Appen, \\ and Richard Dronskowski
}

Institut für Anorganische Chemie, RWTH Aachen University, Landoltweg 1, 52056 Aachen, Germany

Reprint requests to Prof. Dr. Richard Dronskowski. Fax +49-241-80-92642.

E-mail: drons@HAL9000.ac.rwth-aachen.de

Z. Naturforsch. 2010, 65b, 1235-1239; received May 25, 2010

\begin{abstract}
The manganese-rich ternary cementite phase $\mathrm{Mn}_{1.8} \mathrm{Fe}_{1.2} \mathrm{C}$ has been synthesized by a ceramic route in an almost quantitative yield, and the crystal structure refinement on the basis of high-resolution $\mathrm{X}$-ray powder diffraction data using $\mathrm{Mo} K_{\alpha 1}$ radiation has been performed. The carbon atom is found in a slightly distorted trigonal prism composed of $\mathrm{Mn}$ and $\mathrm{Fe}$ atoms, with a rather narrow bond length range from 1.95 to $2.09 \AA$. The magnetic susceptibility data clearly indicate long-range ordering phenomena, in particular dominant antiferromagnetic interactions, as predicted by density-functional theory.
\end{abstract}

Key words: Cementite, Synthesis, Manganese, X-Ray Diffraction, Magnetic Susceptibility

\section{Introduction}

Steel, known for thousands of years, is one of the very few construction materials of paramount importance even in the $21^{\text {st }}$ century, and the simple iron carbide cementite, $\mathrm{Fe}_{3} \mathrm{C}$ (see crystal structure in Fig. 1), is one of its most common ingredients. In order to improve the properties of steel, alloying with manganese has been pursued, because on the one hand, Mn stabilizes the face-centered cubic structure type [1], and on the other hand, it readily dissolves in cementite [2] and, therefore, influences its properties. While the properties of $\mathrm{Fe}_{3} \mathrm{C}$ are known from a large number of scientific contributions, only very few papers have dealt with the isomorphic $\mathrm{Mn}_{3} \mathrm{C}$ and the associated ternaries. Indeed, the preparation of $\mathrm{Mn}_{3} \mathrm{C}$ is not trivial; this very phase readily disproportionates into $\mathrm{Mn}_{23} \mathrm{C}_{6}$ and $\mathrm{Mn}_{7} \mathrm{C}_{3}$ below $970{ }^{\circ} \mathrm{C}$ [3]. There is also a conflict between the experimental finding [4] of an antiferromagnetic ground state for $\mathrm{Mn}_{3} \mathrm{C}$ and a recent theoretical contribution [5] which has suggested a non-magnetic ground state (see also below).

Regarding the ternary phase system $(\mathrm{Mn}, \mathrm{Fe})_{3} \mathrm{C}$, there are a number of chemical compositions that have already been synthesized [6-13], but the investigations were concerned with the structural and thermodynamic properties only; corresponding data about the magnetic structure(s) are not yet available. Moreover,

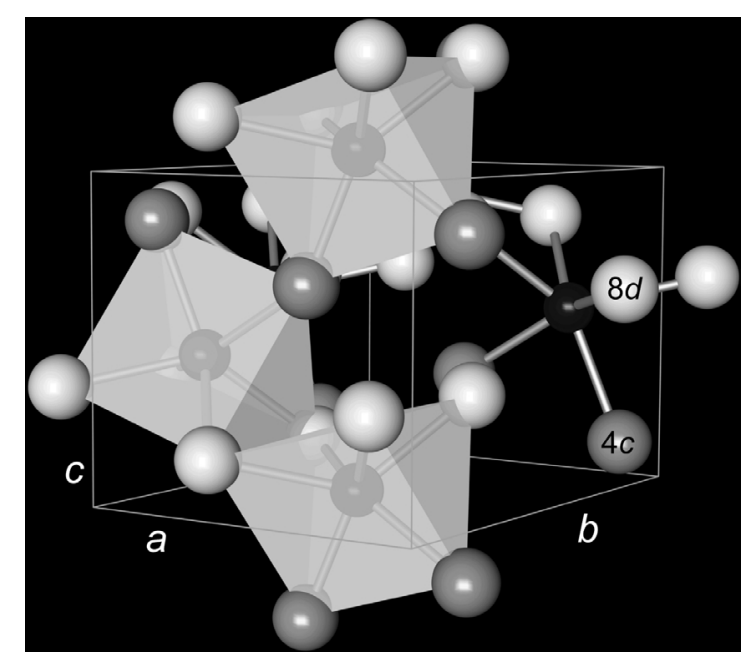

Fig. 1. View into the orthorhombic cementite crystal structure containing both corner- and edge-sharing carboncentered trigonal prisms formed by the metal atoms located on Wyckoff positions $8 d$ (light grey) and $4 c$ (dark grey).

there is no evidence for a structurally ordered phase, and it is believed that these carbides of $\mathrm{Mn}$ and Fe form continuous solid solutions [14]. Because of these fundamental questions, we have recently calculated [15] the phase diagram of cementite $\left(\mathrm{Mn}_{x} \mathrm{Fe}_{1-x}\right)_{3} \mathrm{C}$ over the entire compositional range by using density-functional theory, and these calculations reproduced all the struc- 
tural and magnetic parameters of the binary $\mathrm{Fe}_{3} \mathrm{C}$ quite satisfactorily. In contrast to previous findings, however, we now found a ferrimagnetic ground state for $\mathrm{Mn}_{3} \mathrm{C}$. In addition, the DFT calculations allowed us to divide the ternary compounds into three different groups, depending on the Mn content [15]. Unfortunately, quantum-chemical methods can never exclude the existence of other stable configurations, for example those that require even larger magnetic unit cells, but the calculations do suggest cooperative magnetism for all compositions. Since some of these newer theoretical results contradict previous papers dealing with $\mathrm{Mn}_{3} \mathrm{C}$ or $(\mathrm{Mn}, \mathrm{Fe})_{3} \mathrm{C}$, we believe it is necessary to experimentally reinvestigate these phases, and this has been the motivation of the present study.

\section{Results and Discussion}

Up to the present day, all iron analogs of the manganese carbides (with the exception of $\mathrm{Mn}_{23} \mathrm{C}_{6}$ ) have been reported, and together they form metastable solid solutions. As alluded to already, various synthetic pathways including high-pressure approaches have been explored, and the results clearly reflect the metastability of some of the phases. The preparation of $(\mathrm{Mn}, \mathrm{Fe})_{3} \mathrm{C}$ has been attempted by high-temperature routes involving the metals and elemental carbon, and this is indeed represented by the first synthesis of $\mathrm{Mn}_{3} \mathrm{C}$ ever reported [16]. Alternatively, $\mathrm{Mn}_{3} \mathrm{C}$ was prepared from a reaction between methane and $\mathrm{Mn}$ at $950{ }^{\circ} \mathrm{C}$ [17] or by the reaction between $\mathrm{MnCl}_{2}$ and calcium acetylide, $\mathrm{CaC}_{2}$ [18].

More recently, $\mathrm{Mn}_{3} \mathrm{C}$ was prepared from the elements at $1000{ }^{\circ} \mathrm{C}$, followed by immediate quenching [19]. These contributions further showed that the presence of $5 \%$ Fe stabilizes the cementite structure type. By analyzing isothermal sections of the ternary $\mathrm{Mn}-$ $\mathrm{Fe}-\mathrm{C}$ system it has been found [20] that $\mathrm{Mn}_{3} \mathrm{C}$ is stable even at $1050{ }^{\circ} \mathrm{C}$ and forms solid solutions with $\mathrm{Fe}_{3} \mathrm{C}$. In addition, $\mathrm{Mn}_{5} \mathrm{C}_{2}$ and $\mathrm{Mn}_{7} \mathrm{C}_{3}$ are also stable under these conditions, but they do not coexist with the metallic phase. Finally, cementite phases incorporating $\mathrm{Mn}, \mathrm{Cr}, \mathrm{V}, \mathrm{Ti}, \mathrm{Ni}$, and $\mathrm{Si}$ have been synthesized using tribochemical means (ball mill), followed by a final spark plasma sintering step [21].

In this study, we have observed that the attempt to let the elements react in an electric arc unfortunately does not lead to phase-pure $(\mathrm{Mn}, \mathrm{Fe})_{3} \mathrm{C}$ cementite phases, simply because the high vapor pressure of manganese leads to a depletion of the products in terms of $\mathrm{Mn}$, and one ends up with $\mathrm{Mn}_{5} \mathrm{C}_{2}$ and $\mathrm{Mn}_{7} \mathrm{C}_{3}$ instead. Thus, an excess of manganese is recommended in any such high-temperature routes. The synthesis now accomplished also utilizes a certain excess of Mn and a subsequent quenching step, as shown before [19], required to preserve the freshly made manganese-rich cementite. The almost inevitable presence of a very small $\gamma$-Mn impurity (see below) may be safely tolerated because it does not impede the structural and also magnetochemical analysis.

\section{Structure}

The new structural refinement on the basis of the Rietveld method is the first one ever reported for this manganese-rich cementite phase. Because of the short wave length and, thus, the extraordinarily large number of 1138 Bragg reflections over the $2 \theta$ range between 8 and $110^{\circ}$, the accuracy of this powder work is comparable or better than prior single-crystal work $[6,13]$ which also dealt with more Fe-rich cementites. Fig. 2 allows a visual inspection of the Rietveld refinement quality, for the sake of clarity limited to the narrower $2 \theta$ range between 10 and $60^{\circ}$.

Because of the minute scattering difference between $\mathrm{Mn}$ and Fe, it is impossible to detect any site ordering, should it ever exist, and such an attempt would call for a local probe such as solid-state nuclear magnetic resonance. Instead, the positions of the heavy scatterers were perfectly refined with a mixed $60 / 40 \%$ oc-

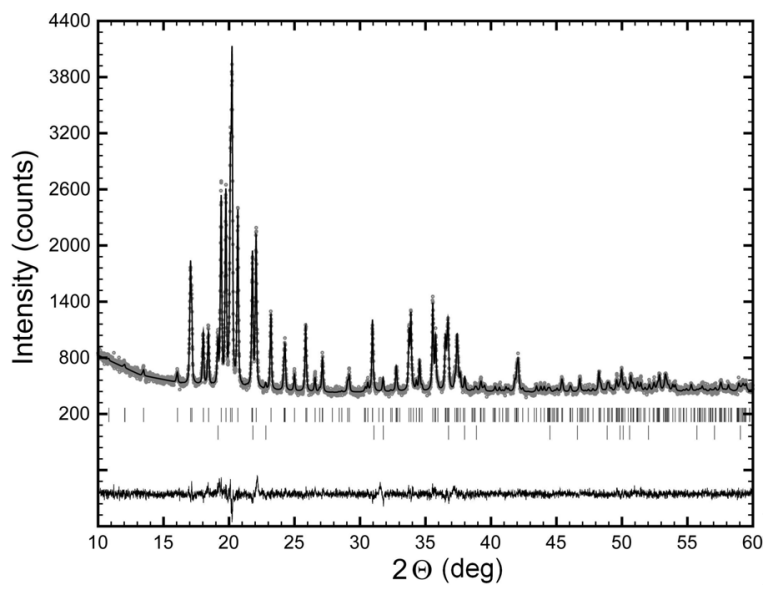

Fig. 2. Result of the Rietveld refinement of $\mathrm{Mn}_{1.8} \mathrm{Fe}_{1.2} \mathrm{C}$ on the basis of $\mathrm{MoK}_{\alpha 1}$ radiation with measured (grey) and refined (black curve) intensities, with the observed Bragg peaks of the main phase (upper bars) and the $3 \% \gamma$-Mn impurity phase (lower bars), as well as the difference-intensity curve (bottom). The total refinement is based on a much wider $2 \theta$ range between 8 and $110^{\circ}$. 
cupancy for $\mathrm{Mn}$ and Fe to account for the chemical composition. The $\mathrm{C}$ atom is nicely resolved, including a very well-behaved isotropic displacement parameter. On the basis of the lattice and spatial parameters, the carbon atom is found in a distorted trigonal prism by $\mathrm{Mn}$ and $\mathrm{Fe}$ atoms, and the six shortest bonds amount to $1.95(1), 2 \times 1.979(7), 2.06(1)$ and $2 \times 2.086(8) \AA$, just as expected. Below $3 \AA$, the interatomic distances between the $\mathrm{Mn}$ (and $\mathrm{Fe}$ ) atoms are quite homogeneous, namely between 2.503(2) and 2.694(3) A.

\section{Magnetism}

The magnetic susceptibility data of the compound $\mathrm{Mn}_{1.8} \mathrm{Fe}_{1.2} \mathrm{C}$ measured between 2 and $290 \mathrm{~K}$ at field strengths between 0.01 and $5.0 \mathrm{~T}$ indicate long-range ordering phenomena; an overview is given in Fig. 3. The low-field data exhibit a continuous decrease of the effective Bohr magneton number (cgs-units: $\mu_{\mathrm{eff}}=$ $2.8279 \sqrt{\chi T})$ upon going from r.t. $\left(\mu_{\text {eff }}=2.5\right)$ to $2 \mathrm{~K}$ $\left(\mu_{\text {eff }}=0.25\right)$, seemingly approaching an antiferromagnetic ground state. At $c a$. $35 \mathrm{~K}$, a weak phase transition is clearly visible as a field-dependent shoulder in the reciprocal susceptibility that is quenched at $H>$ $1 \mathrm{~T}$. Nonetheless, no frequency dependence in the AC susceptibility $(10-1500 \mathrm{~Hz})$ is observed in this temperature region. Above this transition, the continuous divergence of the field-dependent data is possibly due to ferrimagnetic ordering.

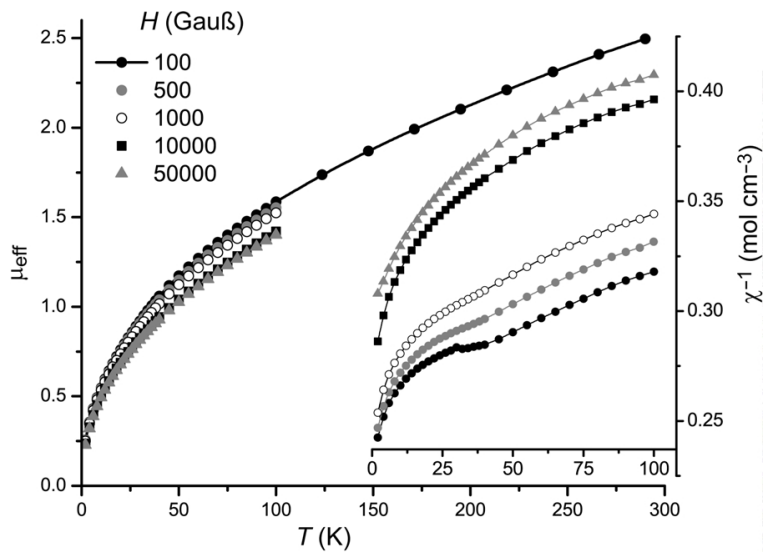

Fig. 3. Temperature dependence $(2-290 \mathrm{~K})$ of the effective Bohr magneton number $\mu_{\text {eff }}$ of $\mathrm{Mn}_{1.8} \mathrm{Fe}_{1.2} \mathrm{C}$ in external fields ranging from 100 to $50.000 \mathrm{Gau}$. Note that the fielddependent spread of the $\mu_{\mathrm{eff}}(H)$ curves decreases towards lower temperatures and appears to approach an antiferromagnetic ground state. Inset: plots of the reciprocal susceptibility $(2-100 \mathrm{~K})$ highlighting the apparent magnetic phase transition at $c a .35 \mathrm{~K}$. This transition is readily quenched with increasing external fields.
This experimental information may be compared with the results of the recent theoretical assessment of the $\left(\mathrm{Mn}_{x} \mathrm{Fe}_{1-x}\right)_{3} \mathrm{C}$ phase diagram [15] by means of density-functional theory. The composition of $\mathrm{Mn}_{1.8} \mathrm{Fe}_{1.2} \mathrm{C}$ is located at the Mn-rich end of the so-called "middle" group of that phase diagram. For these compounds, with Mn contents corresponding to a chemical composition close to $\mathrm{Mn}_{1.75} \mathrm{Fe}_{1.25} \mathrm{C}$, the calculations yield ferrimagnetic $8 d$ layers composed of $(\mathrm{Fe}-\mathrm{Mn}-)_{n}$ chains and ferromagnetic $4 c$ interlayers. The aforementioned $\mathrm{Mn}_{1.75} \mathrm{Fe}_{1.25} \mathrm{C}$ has a theoretically predicted average local moment of about $1.1-$ $1.2 \mu_{\mathrm{B}}$ per metal atom which translates into a saturation moment of $0.5 \mu_{\mathrm{B}}$ per formula unit. Thus, the experimental measurements nicely corroborate the predicted dominating antiferromagnetic interactions. Because we have not achieved magnetic saturation in the experiment, however, it is pointless to compare the observed low-temperature atomic magnetic moment $\left(\mu_{\mathrm{a}}=0.06 \mu_{\mathrm{B}}\right.$ at $\left.2 \mathrm{~K}\right)$ with the theoretically predicted saturation moment, in particular since the magnetic structure is unknown. In order to reveal the latter, (spin-polarized) neutron diffraction experiments are required.

\section{Conclusion}

Magnetic susceptibility data on structurally wellcharacterized $\mathrm{Mn}_{1.8} \mathrm{Fe}_{1.2} \mathrm{C}$ indicate long-range antiferromagnetic ordering, in good agreement with preceding density-functional calculations. In order to solve the magnetic structure, neutron diffraction measurements are needed, and these are under preparation at the very moment.

\section{Experimental Section}

To synthesize $\mathrm{Mn}_{1.8} \mathrm{Fe}_{1.2} \mathrm{C}$, a mixture of $20 \mathrm{mmol} \mathrm{Mn}$, $10 \mathrm{mmol} \mathrm{Fe}$ and $9 \mathrm{mmol} \mathrm{C}$ was pressed into a pellet using a pressure of approx. $0.5 \mathrm{GPa}$. The pellet was transferred into a quartz tube which was evacuated and then sealed. After heating at $1030{ }^{\circ} \mathrm{C}$ for $24 \mathrm{~h}$ the quartz tube was quenched in ice water. Note that slow cooling below $950{ }^{\circ} \mathrm{C}$ leads to the formation of other impurity phases, as evident from $\mathrm{X}$-ray powder diffraction data. The material has a greyishmetallic but also brittle appearance. The chemical analysis of $\mathrm{Mn}_{1.8} \mathrm{Fe}_{1.2} \mathrm{C}$ was conveniently based on the unit-cell volume, as given below.

\section{$X$-Ray structure determination}

The X-ray diffraction data were measured at $r$.t. with the help of a Stoe STADI MP powder diffractometer in transmis- 


\begin{tabular}{lllll}
\hline & & $\mathrm{Mn}_{1.8} \mathrm{Fe}_{1.2} \mathrm{C}$ & $\mathrm{Mn}_{1.2} \mathrm{Fe}_{1.8} \mathrm{C}[6]$ & $\mathrm{Mn}_{0.3} \mathrm{Fe}_{2.7} \mathrm{C}[13]$ \\
& Space group, no., $Z$ & $P n m a, 62,4$ & $P n m a, 62,4$ & $P n m a, 62,4$ \\
\hline Lattice & $a, \AA$ & $5.0764(6)$ & $5.074(2)$ & 5.0598 \\
parameters & $b, \AA$ & $6.7667(8)$ & $6.757(3)$ & 6.7462 \\
& $c, \AA$ & $4.5229(6)$ & $4.521(2)$ & 4.5074 \\
Mn1 $(60 \%)$ and & $x$ & $0.1816(4)$ & $0.1816(3)$ & $0.1816(3)$ \\
$\mathrm{Fe} 1(40 \%)$ on $8 d$ & $y$ & $0.0650(4)$ & $0.0666(1)$ & $0.0666(1)$ \\
& $z$ & $0.3401(8)$ & $0.3374(2)$ & $0.3374(2)$ \\
$\mathrm{Mn} 2(60 \%)$ and & $B, \AA^{2}$ & $0.16(4)$ & - & 0.26 \\
$\mathrm{Fe} 2(40 \%)$ on $4 c$ & $z$ & $0.0364(5)$ & $0.0367(4)$ & $0.0367(4)$ \\
& $B, \AA^{2}$ & $0.8418(9)$ & $0.8402(2)$ & $0.8402(2)$ \\
$\mathrm{C}$ on 4c & $x$ & $0.13(6)$ & - & 0.31 \\
& $z$ & $0.863(4)$ & $0.878(4)$ & $0.877(3)$ \\
& $B, \AA^{2}$ & $0.431(4)$ & $0.442(4)$ & $0.444(2)$ \\
\hline
\end{tabular}

Table 1. Crystal structure data for $\mathrm{Mn}_{1.8} \mathrm{Fe}_{1.2} \mathrm{C}$ and related phases for comparison. sion geometry using strictly monochromatized $\mathrm{Mo} K_{\alpha 1}$ radiation $(\lambda=0.70932 \AA)$. The $2 \theta$ range was very wide, between $8-110^{\circ}$. After having used the lattice parameters of the known but less manganese-rich phase $\mathrm{Mn}_{1.2} \mathrm{Fe}_{1.8} \mathrm{C}$ [6] as starting values, the diagram was easily indexed, and one additional Bragg reflection was identified as belonging to a small $\gamma$-Mn impurity. The subsequent FULLPROF [22] refinement by means of a pseudo-Voigt profile including an asymmetry correction for the low-angle region indeed revealed the presence of $3 \% \gamma-\mathrm{Mn}$, with the remaining $97 \%$ belonging to the $\mathrm{Mn}_{1.8} \mathrm{Fe}_{1.2} \mathrm{C}$ cementite phase; the latter was refined with $60 \% \mathrm{Mn}$ and $40 \% \mathrm{Fe}$ scattering contributions on the $8 d$ and $4 c$ positions such as to reflect the actual composition. The latter directly follows from the unit-cell volume $\left(155.36 \AA^{3}\right.$ ) which lies between those of $\mathrm{Mn}_{2.7} \mathrm{Fe}_{0.3} \mathrm{C}\left(156.83 \AA^{3}\right)$ and $\mathrm{Mn}_{1.5} \mathrm{Fe}_{1.5} \mathrm{C}\left(154.80 \AA^{3}\right)$, and these are known to scale with the manganese content [7]. Table 1 shows all the relevant refined parameters which are based on a total of $1138 \mathrm{Bragg}$ reflections for $\mathrm{Mn}_{1.8} \mathrm{Fe}_{1.2} \mathrm{C}$. The profile residual value converged to 0.036 , the Bragg $R$ value of the main phase to 0.063 . To allow for more realistic standard deviations, all automatically refined ones were manually multiplied by a factor of 2 .
Further details of the crystal structure investigation may be obtained from Fachinformationszentrum Karlsruhe, 76344 Eggenstein-Leopoldshafen, Germany (fax: +49-7247808-666; e-mail: crysdata@ fiz-karlsruhe.de, http://www.fizinformationsdienste.de/en/DB/icsd/depot_anforderung.html) on quoting the deposition number CSD-421830.

\section{Magnetic measurement}

The magnetic DC susceptibility of polycrystalline $\mathrm{Mn}_{1.8} \mathrm{Fe}_{1.2} \mathrm{C}$ was recorded between 2 and $290 \mathrm{~K}$ in static fields ranging from 100 to $50.000 \mathrm{Gau} ß$ using a Quantum Design MPMS-5XL SQUID magnetometer. Ca. $60 \mathrm{mg}$ of a microcrystalline sample were compressed into a cylindrical PTFE sample holder; resulting susceptibilities were corrected for sample holder contributions. AC susceptibility data were recorded within $10-50 \mathrm{~K}$ using frequencies up to $1500 \mathrm{~Hz}$; no frequency-dependence or out-of-phase components were observed.

\section{Acknowledgement}

Financial support of the collaborative research center 761 (Stahl $a b$ initio) of the Deutsche Forschungsgemeinschaft is gratefully acknowledged.
[1] C. Y. Chao, T.F. Liu, Met. Trans. A 1993, 24, $1957-$ 1963.

[2] M. Umemoto, Z. G. Liu, K. Masuyama, K. Tsuchiya, Acta Mater. 2001, 45, 391 - 397.

[3] A. Tanaka, Trans. Jpn. Inst. Met. 1979, 20, 516-522.

[4] L. T. Domasevich, V.F. Kolotun, T. Y. Kosolapova, V.F. Nemchenko, Inorg. Mater. 1977, 13, $1733-$ 1735.

[5] J. H. Jang, I. G. Kim, H. K. D. H. Bhadeshia, Mater. Sci. Forum 2010, 638-642, 3319-3324.

[6] M. J. Duggin, D. Cox, L. Zwell, Trans. Met. Soc. AIME 1966, 236, $1342-1346$.

[7] R. Benz, J. F. Elliott, J. Chipman, Met. Trans. 1973, 4, $1975-1986$.
[8] M.P. Arbuzov, E. A. Zhurakovsky, G. V. Zolotareva, B. I. Kotlyar, Inorg. Mater. 1974, 10, 1246-1250.

[9] A. Kagawa, T. Okamoto, Trans. Jpn. Inst. Met. 1979, $20,659-666$

[10] A. Rouault, R. Fruchart, Ann. Chim. 1970, 5, 335 - 340.

[11] P. Lesage Bourdon, A. Michel, C.R. Hebd. Séances Acad. Sci. 1958, 246, 2624-2627.

[12] T. Shigematsu, S. Ohmori, N. Nakanishi, S. Kachi, J. Phys. Soc. Jpn. 1975, 38, 1213.

[13] E. J. Fasiska, G. A. Jeffrey, Acta Crystallogr. 1965, 19, $463-471$

[14] V. Kuznetsov, Iron Systems, Part 2, in Landolt-Börnstein - Group IV Physical Chemistry, Volume 11D2, Springer Verlag, Berlin, Heidelberg 2008. 
[15] J. von Appen, B. Eck, R. Dronskowski, J. Comput. Chem., 2010, 31, 2620-2627.

[16] L. Troost, P. Hautefeuille, C.R. Hebd. Séances Acad. Sci. 1875, 80, 909-911.

[17] P. Pingault, Ann. Chim. 1933, 20 (Ser. 10), 371-438.

[18] L. M. Bullier, Patentschrift DE-118177 (Kaiserliches Patentamt) 1901.
[19] G. J. W. Kor, Met. Trans. B 1979, 10, 397 - 400.

[20] K. Kuo, L. E. Persson, J. Iron Steel Inst. 1954, 178, 39 44.

[21] M. Umenoto, Z. G. Liu, H. Takaoka, M. Sawakami, K. Tsuchiya, K. Masuyama, Met. Mater. Trans. A 2001, 32, 2127-2131.

[22] J. Rodriguez-Carvajal, Physica B 1993, 192, 55-69. 